\title{
Manipulating the onset of lambing season in communal ewes through hormonal intervention
}

\author{
J.M. Rust", S. Mthi \& T. Rust \\ Döhne Agricultural Development Institute, Private Bag X15, Stutterheim, 4930, South Africa
}

(Received 11 December 2019; Accepted 9 March 2020; First published online 10 April 2020)

\begin{abstract}
Copyright resides with the authors in terms of the Creative Commons Attribution 4.0 South African Licence.
See: http://creativecommons.org/licenses/by/4.0/za

Condition of use: The user may copy, distribute, transmit and adapt the work, but must recognise the authors and the South African Journal of Animal Science.
\end{abstract}

\begin{abstract}
The study was conducted to evaluate the effectiveness of using long-acting medroxyprogesterone acetate (MPA) to delay the lambing season in communal wool sheep ewes. The study was conducted in three phases. In phase 1, a random assessment was made to determine whether the hormone had any effect on delaying the onset of the lambing season. In the second phase, the administration of the hormone at different times during the perceived mating season was assessed. In the third phase, it was investigated whether the use of the hormone had residual effects in the subsequent lambing season after the treatment was discontinued. From the results it is evident that the administration of $150 \mathrm{mg}$ MPA before conception could delay lambing between two and three months. November seems to be the optimum month for hormone administration. However, administration of the hormone did not guarantee effective prevention of conception in all treated ewes and discontinuation of treatment resulted in ewes reverting to pre-treatment lambing patterns. In conclusion, long-acting MPA can be used selectively as an effective method to delay the lambing season in communal ewes and to manipulate it towards more favourable environmental conditions for ewes and lambs. There can be a seasonal effect on time of conception in communal ewes and this should be considered when timing a hormonal treatment protocol.
\end{abstract}

Keywords: communal sheep farming, lambing season, manipulation, medroxyprogesterone acetate

\# Corresponding author: jean.rust@gmail.com

\section{Introduction}

Lambing times of sheep breeds in sub-tropical and tropical environments tend to be semi or completely aseasonal, with the quality and availability of feed dictating breeding activity (Thimonier et al., 1986). In most ovine breeds, the breeding season starts in late summer and lasts to early autumn (Chemineau et al., 1992). Its length varies widely among breeds, but in general it ends in winter (Hafez, 1952).

Fertility control in animals should preferably be temporary and reversible (Porton \& Hornbeck, 1993). The control and prevention of contraception in livestock has a long history. It was used in female camels in caravans and in war in the Near East, Arabia, Africa, and Asia. In these instances, pebbles were introduced into the uterus during oestrus via the cervical canal, which then functioned as foreign bodies to prevent conception (Patton et al., 2007). Research and development of hoof stock contraceptives were driven by the need to control reproduction in male and female animals in free roaming and in captive situations (Patton et al., 2007). Techniques were developed that used the experience gained from fertility control work on domesticated ungulates, rodents and primates, including the human female. The commercial availability of synthetic steroid hormones aided in the development of these methodologies (Patton et al., 2007). From domesticated and wildlife perspectives, several studies have shown the efficacy and safety of specific contraceptives and the potential for improving animal welfare by controlling reproduction selectively (Turner \& Kirkpatrick, 2002). Contraception can take many forms and methods that have been documented that include surgical sterilization (Jöchle et al., 1973; DeMatteo et al., 2005), mechanical methods (Nie et al., 2003; Turin et al., 1997; Fordyce et al., 2001; Matschke, 1976; Daels \& Hughes, 1995), steroid hormones (Denicola et al., 1997; Jacobson et al., 1995; Burns et al., 1993; Patton et al., 2007; Chang, 1985; Patton et al., 2005; Zimbelman et al., 1970; Raphael et al., 1992), protein hormones (Maclellan et al., 1997; D'Occhio et al., 2002; McNeilly \& Fraser, 1987; Brussow et al., 1996), and immunocontraception (Paterson \& Aitken, 
1990; Kirkpatrick et al., 1996; Frank \& Kirkpatrick, 2002; Frank et al., 2005; Dunbar et al., 2001; Munson, 2002; Clarke et al., 1979; Esbenshade \& Brit, 1985; Patton et al., 1991; Johnson et al., 1988; Garza et al., 1986; Keeling \& Crighton, 1984).

Sheep farming, and specifically wool production as a by-product of sheep farming, forms an integral part of the commodities produced by the emerging farming sector in the areas that were previously known as Ciskei and Transkei. This is the only branch of livestock production that has shown promise of and some degree of improvement in the recent past. Substantial efforts have been put into the genetic and technical intervention sides of the wool production chain. Organizations such as the National Wool Growers Association (NWGA) and Eastern Cape Department of Agriculture have made concerted efforts to provide the inputs to continuously improve wool production in these areas. Inputs such as the genetic improvement of rams, improvement of infrastructure and technical training in all aspects of wool production have led to the substantial improvement of wool quality and quantity and consequent enhanced income to the farmer (Rust et al., 2015).

Although emphasis has been put on the improvement of certain elements in the wool production chain, the basic management of wool sheep is still at sub-optimum level. Nutritional and reproduction management are two elements that require urgent attention for the remainder of the production chain to continue with its current trend of improvement. If not, these two elements may become 'killer assumptions' in the whole equation (personal observation, unpublished).

Currently in nutritional and reproduction management, the grazing resource is under constant pressure, with the most critical period being the winter months of June, July, and August and, to some extent, September. Spring, summer and autumn are not so critical, with the grazing resource being able to support animal numbers then. Little or no supplementation is supplied through the summer and winter periods (Bembridge, 1984).

The breeding and lambing pattern more or less follows the availability of feed. Most ewes reach their optimum body condition at the beginning of summer, and conceive and lamb in mid-winter. The problem with this pattern is that the mortality rates among ewes and more so among lambs are extremely high in these difficult periods. Lamb mortality rates of between $60 \%$ and $80 \%$ are common in the area in which the study was conducted (personal observation, unpublished). The mortality rate among ewes can probably be attributed to complications during lambing, starvation, and exposure to extreme weather conditions. Mortality of lambs can probably be ascribed to abandonment in addition to the factors leading to the death of their dams. Body condition maintenance and growth rates are severely affected in both adults and offspring (Bembridge, 1984; Steyn, 1982).

At present this pattern cannot be corrected because controlled breeding is not practised. There is no camp system, and males and females cannot be separated at certain times of year. Even if individual farmers should attempt controlled breeding, their efforts would be nullified because other community members in the communal system would not conform (Bembridge, 1984).

This then becomes a vicious cycle, and the same reproductive and lambing pattern is repeated year after year. All of this is dictated by the availability of feed and the body condition of the reproductively active ewes. This results in few young animals being available for marketing, selection and replacement of old stock. There is limited observed evidence that ewes that do lamb outside this pattern tend to remain in that altered pattern (personal observation, unpublished).

There are two possible ways of changing lambing season patterns in communal sheep flocks. One is to put the infrastructure in place to separate ewes and rams, and to permit breeding only during late summer and autumn, which would allow for lambing to take place in spring. However, this would be costly and time consuming because this infrastructure is currently non-existent in most areas. The second theoretical option is to manipulate the reproductive cycle of the breeding animals artificially at physiological and hormonal level (personal observation, unpublished).

In this study, an attempt was made to assess whether intervention at hormonal level could be effective. If so, what is the optimum time for intervention and could it affect a permanent shift in a seasonal lambing pattern?

\section{Materials and Methods}

The study was conducted in three phases. The first stage was done on a limited scale with a relatively small number of ewes in two communities, namely Qobo Qoba, Centane, which is located at $32^{\circ} 25^{\prime} 46.39^{\prime \prime} \mathrm{S}$; $28^{\circ} 15^{\prime} 24.92^{\prime \prime} \mathrm{E}$ (Bhisho Thornveld) and Ntseshe-Ngqamakwe at $32^{\circ} 05^{\prime} 59.50^{\prime \prime S}$; $28^{\circ} 05^{\prime} 20.93^{\prime \prime} \mathrm{E}$ (Mthatha Moist Grassland)) (Mucina \& Rutherford, 2006). This was treated as a pilot trial to assess whether there was value in using a specific hormone and treatment protocol. In the second phase, animals were treated during various months of the mating season to assess the optimum time of treatment. In the third phase, treatment was done according to the best protocol that had been established in the second phase and was 
discontinued in the subsequent breeding cycle to assess whether there was a residual effect after the hormonal intervention in the previous mating season. In all instances, four-tooth full-mouth ewes were used. Ethical clearance was obtained from the Döhne ADI Ethical Committee (Ethical certificate no. 5/2012).

In Phase 1 an attempt was made to delay conception and consequent lambing through a high dose of long-acting MPA. Twenty $(n=20)$ experimental ewes in two communities (Qobo Qobo and Ntseshe) $(n=10$ per location) were treated with a single intramuscular administration of $150 \mathrm{mg}$ MPA (Depo-Provera, Pfizer, New York City) in mid-December. This period was selected based on historical information about the possible time of conception. All treated ewes were examined ultrasonically (Sonoscape AV5, Sonoscape Medical Corporation, Shenzhen, China) in an attempt to exclude, as far as possible, any pregnancies at the time of the hormonal treatment. The remainder of the ewes $(n=137)$ in the two flocks were used as controls. The customary open mating season was practised, and ewes were exposed to the rams at all times. All ewes (treatment + control) were examined ultrasonically each month from April to September and their pregnancy status and gestation stage were recorded. However, only the cumulative lambing percentage per group was used as a dependent variable.

Communal ewes from two flocks in the same community (Ntseshe) were used in Phase 2. Randomly selected ewes from each flock were treated with $150 \mathrm{mg}$ MPA (Depo-Provera, Pfizer Inc., New York City) in mid-November (T1) $(n=20)$, mid-December (T2) $(n=20)$, and mid-January (T3) $(n=20)$. The rest of the ewes $(n=150)$ from the two flocks were used as a control. Ewes were exposed to an open mating season as traditionally practised in the communal areas of the Eastern Cape. During the first mating season of Phase 3, randomly selected ewes from each flock were again treated with $150 \mathrm{mg}$ MPA (Depo-Provera, Pfizer) in mid-November $(T)(n=60)$ and the rest of the ewes from these flocks $(n=200)$ were used as a control. Other procedures in Phase 3 were similar to those of Phase 2.

In the next year and subsequent mating season, the hormonal treatment was discontinued to assess whether there was a residual effect on lambing patterns. The group of ewes that had been treated earlier was again compared with the rest of the flock, but the hormonal treatment was not used. All ewes were subjected to the same reproduction status evaluation as in previous phases of the study.

The descriptive statistics and ANOVA modules of Statistica 13.2 (Statsoft) were used to calculate means and standard deviations and analysis of variance for the dependent variables.

\section{Results and Discussion}

Cumulative lambing percentage for the pilot trial was recorded from April to September. Some of the ewes in the treatment group started to lamb in April, whereas ewes in the control group started to lamb only in June. This was earlier than anticipated, but was predicted by the ultrasound profile. It also have indicated that the lambing season was not well defined and that some ewes might have been at an early stage of pregnancy at the time of treatment. However, the start of lambing was not important, but the months in which the bulk of the ewes lambed. There was a shift in the total number of ewes that lambed each month between the treatment and control groups as recording progressed over time. The lambing profiles of treatment and control groups are depicted in Figure 1.

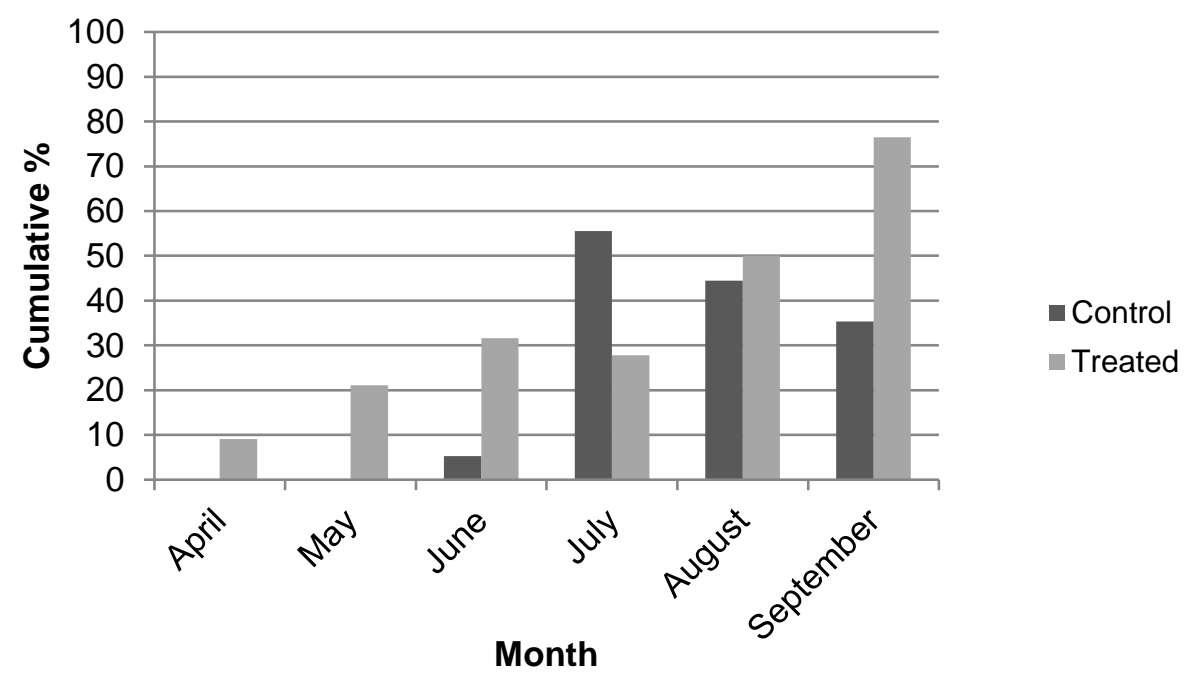

Figure 1 Cumulative lambing profile of ewes after treatment with medroxyprogesterone acetate in December 
In June and July, the cumulative percentage of ewes that finished lambing for the treatment group were $31.6 \%$ and $27.8 \%$, respectively. In the same months the figures were $5.3 \%$ and $55.6 \%$ for the control group. The highest cumulative percentage $(55.6 \%)$ of ewes that finished lambing in the control group was recorded in July. The highest cumulative percentage (76.5\%) of ewes which finished lambing in the treatment group was recorded in September. The cumulative lambing percentage differed $(P<0.05)$ in May, June, July and September. A shift of approximately two months was observed, which corresponded with the findings of Patton et al. (2005) that MPA] was effective in preventing conception for one to three months in various animal species. Patton et al. (2005) found that treatment had to be repeated at a dosage of $2-5 \mathrm{mg}$ per kilogram every 2 - 3 months to suppress conception continuously.

It was deduced that treatment in December had an effect on cumulative lambing because a shift was detected. However, the optimum month for treatment still had to be determined. Because the December treatment had some effect, it was decided to administer MPA in from November to January.

To obtain comparative results, cumulative lambing percentages were recorded from March to October to allow for a longer recording period. The cumulative lambing profiles for T1, T2, T3, and the control group from May to October are depicted in Figures 2, 3, and 4, respectively.

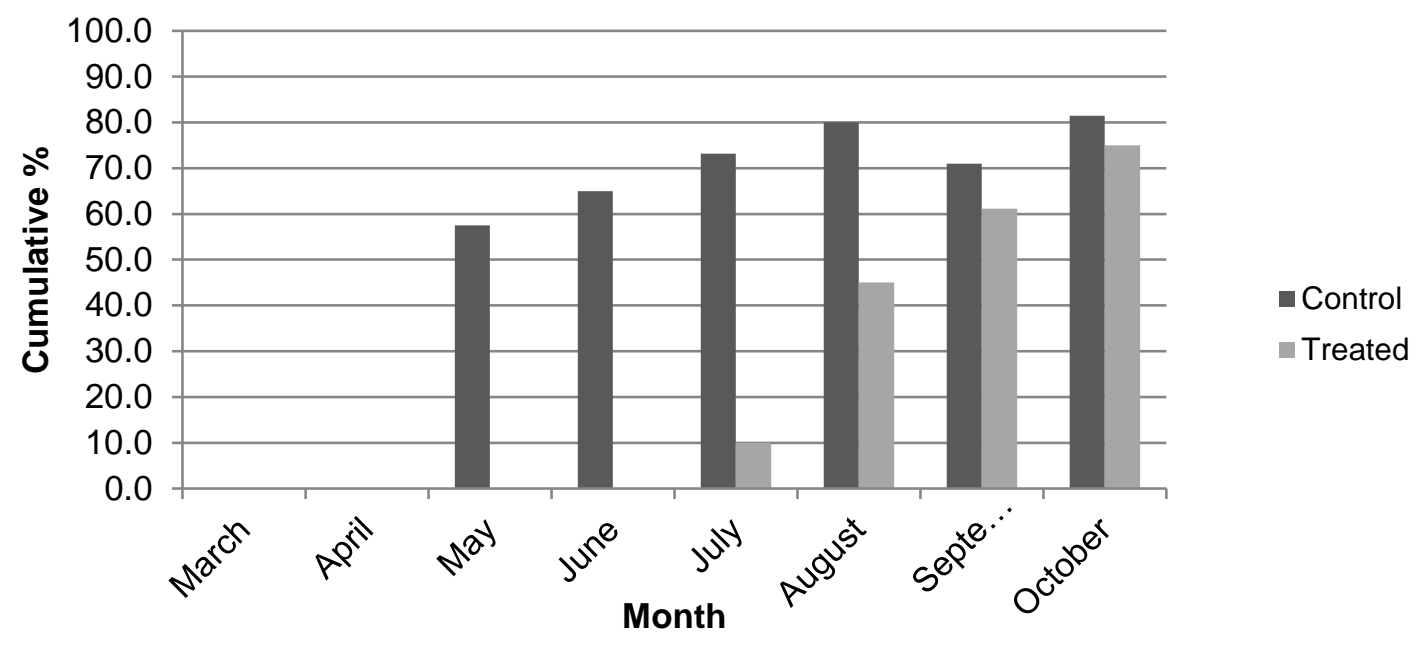

Figure 2 Comparison of lambing profiles of ewes treated with medroxyprogesterone acetate in November and control ewes

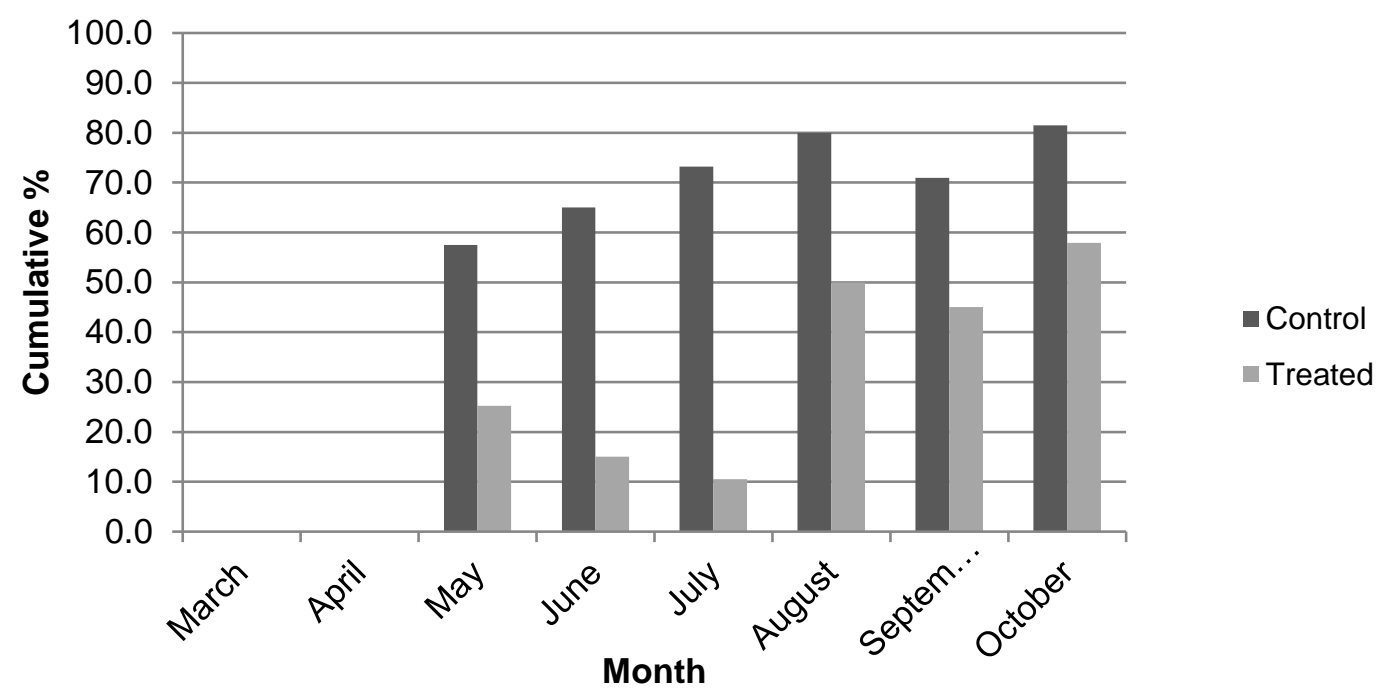

Figure 3 Comparison of lambing profiles of ewes treated with medroxyprogesterone acetate in December and control ewes 


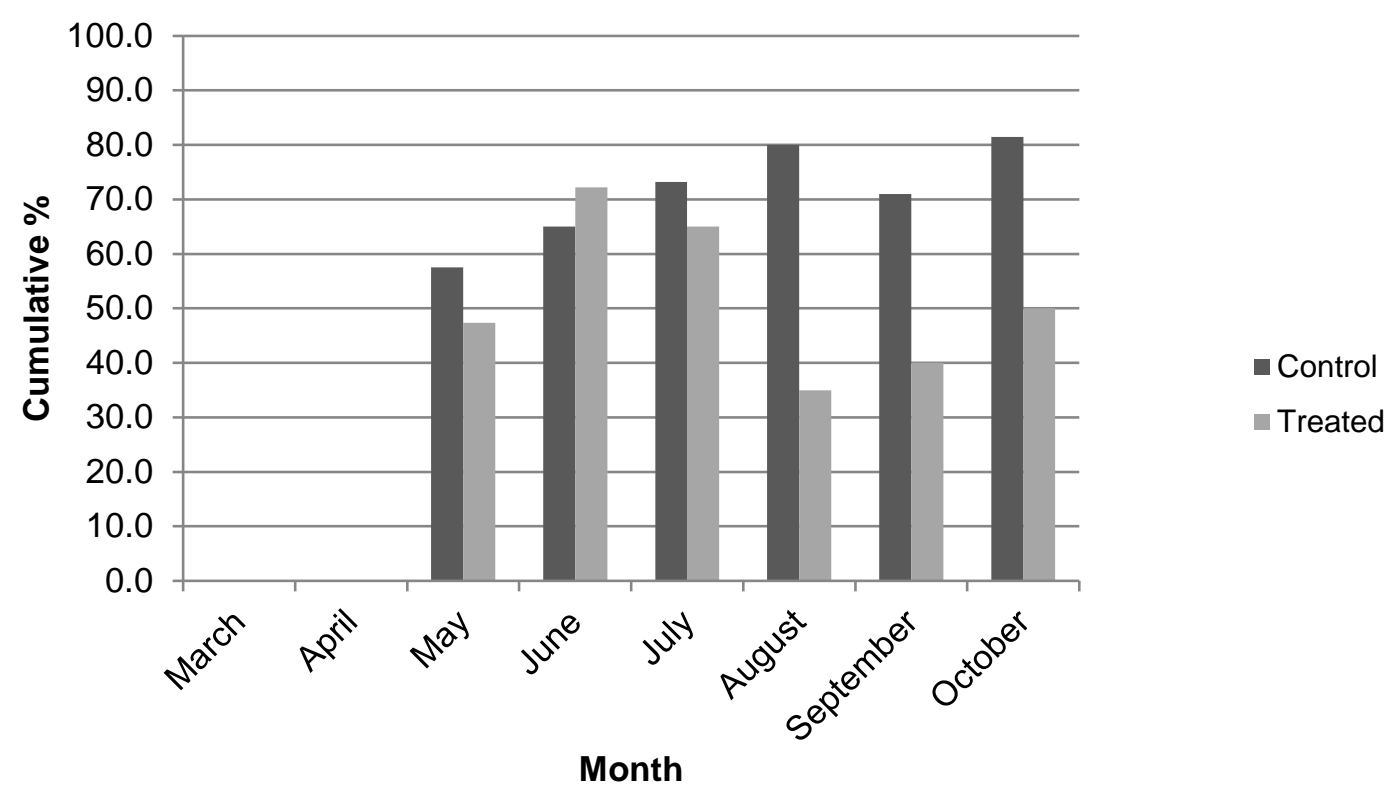

Figure 4 Comparison of lambing profiles of ewes treated with medroxyprogesterone acetate in January and control ewes

As in the pilot trial, the bulk of ewes subjected to T1 and T2 lambed later compared with T3 and control. The T1 and T2 treatments differed significantly in May and August $(P<0.05)$. There were no significant differences for these two treatments for the rest of the evaluation period $(P>0.05)$. The T1 and T2 treatments did differ significantly from the T3 and control in May, June and July $(P<0.05)$. However, the T1 treatment differed $(P<0.05)$ from the control in May, June, July, and August. There were no significant differences between T3 and control for the whole evaluation period $(P>0.05)$. All treatments and the control did not differ significantly during September and October $(P>0.05)$. The change in cumulative lambing season was more pronounced in the November treatment (T1). This suggested that November was the optimum time for treatment and again corresponded with the findings of Patton et al. (2005), who found a one to three month delay in the lambing season when a dosage of $2-5 \mathrm{mg}$ per kilogram of medroxyprogesterone acetate was administered in various species.

Phase 3 was carried out over two production cycles. During the first cycle, treatment was applied at the optimum time as determined during phase 2, namely in mid-November. In the second cycle of Phase 3 , treatment ceased and animals were allowed to conceive and lamb naturally. The results from Phase 3 are depicted in Figure 5 (first cycle) and Figure 6 (second cycle). 


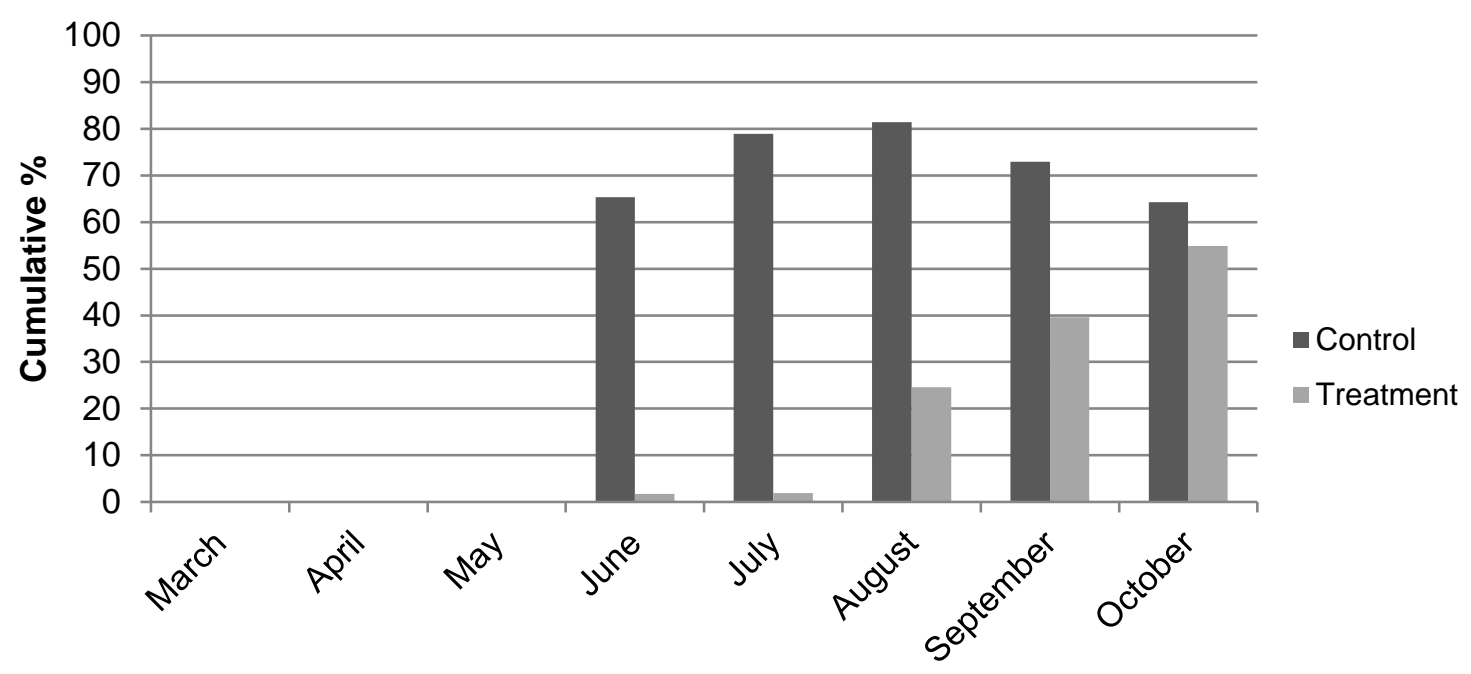

Month

Figure 5 Comparison of lambing profiles of ewes treated with medroxyprogesterone acetate in midNovember and control

In production cycle 1 the treatment resulted in lambing percentages of $1.75 \%, 1.9 \%, 24.6 \%, 39.6 \%$, and $54.9 \%$ in June, July, August, September, and October, respectively. The control group had $65.3 \%$, $78.9 \%, 81.4 \%, 72.9 \%$, and $64.3 \%$ cumulative lambing rates in the same period. The treatment group differed $(P<0.05)$ from the control in June, July and August. This result is similar to the November treatment in Phase 2, which was expected and was indicative of the replicability of the hormonal intervention. This, again, corresponded with the results recorded by Patton et al. (2005).

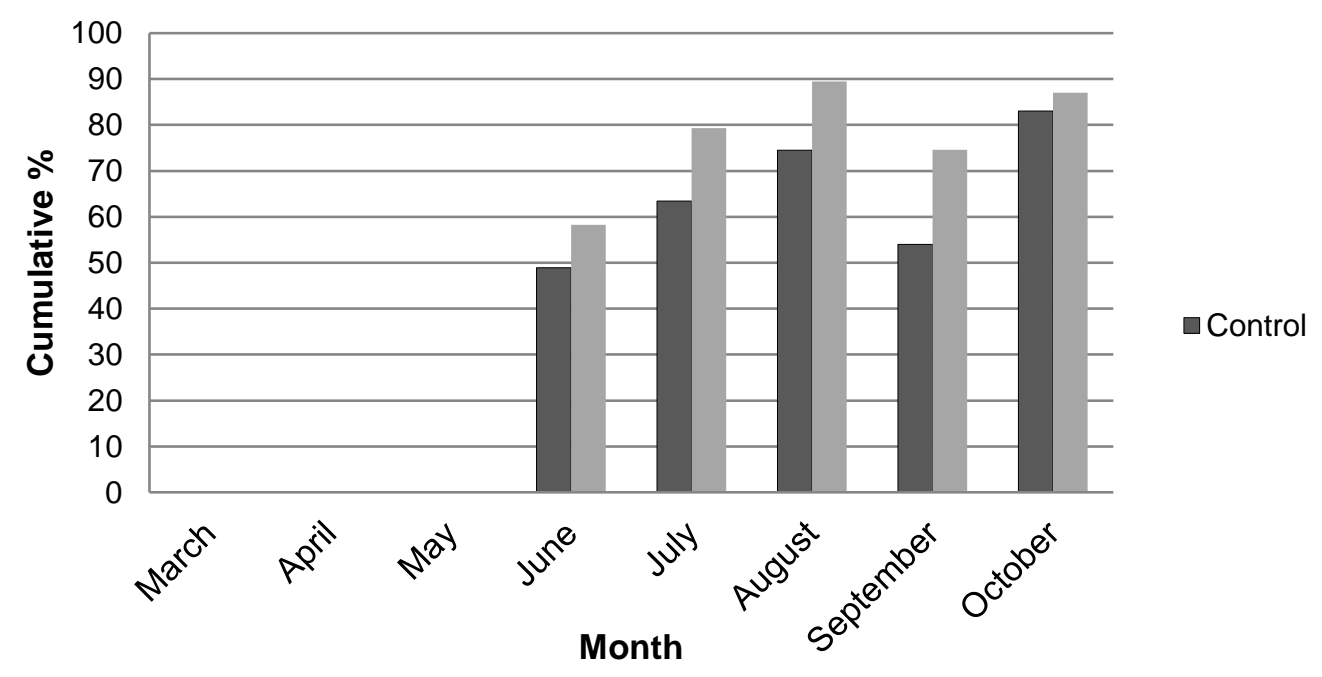

Figure 6 Comparison of lambing profiles of ewes whose treatment with medroxyprogesterone acetate was discontinued and control

After treatment was discontinued (production cycle 2), the treatment group had cumulative lambing percentages of $58.3 \%, 79.3 \%, 89.5 \%, 74.6 \%$, and $87.0 \%$ for June, July, August, September, and October, respectively. In the same period, the control group had cumulative lambing percentages of $48.9 \%, 63.4 \%$, $74.5 \%, 54 \%$, and $83 \%$. There was no significant difference in cumulative lambing rate between the group that had been treated in the previous cycle and the control in cycle 2. This indicated that there was no 
residual effect and ewes reverted to the pre-treatment cycle when treatment was discontinued. There was no evidence in the literature to support this finding. Patton et al. (2005) found that treatment had to be repeated every two to three months to suppress conception continuously.

\section{Conclusions}

The use of a single dose of $150 \mathrm{mg}$ MPA administered before mating can delay lambing for two to three months. This was applicable to the set of conditions under which the hormonal protocol was evaluated in this study. Mid-November seems to be the optimum time for hormone administration. However, administration of the hormone does not guarantee effective conception prevention in all treated ewes, and discontinuation of treatment would result in ewes reverting to pre-treatment lambing patterns. Long-acting MPA could be used selectively as an effective method to delay the lambing season in communal ewes and to manipulate it towards more favourable environmental conditions for ewes and lambs. In addition, the hormonal intervention protocol could be used to protect more vulnerable ewes from environmental stressors during the lambing season. It could be used effectively to evaluate the effects of alternative lambing seasons on lamb mortality and growth performance, and to compare with offspring produced during the traditional winter lambing season. The timing of spring rain remains the major determining factor for the onset of reproductive cycling in communal ewes, which should be considered when applying this protocol. The start of the rainy season and the interaction with the hormonal protocol should be further investigated. Although this protocol could be useful, effective and more practical methods should be developed to alter the lambing season situation in the communal sheep sector.

\section{Authors' Contributions}

JMR conceived and designed the study; JMR, SM and TR collected and analysed the data; JMR drafted the original manuscript, which was reviewed, revised and approved by authors.

\section{Conflict of Interest Declaration}

The authors have no conflicting interests that would impinge on this work.

\section{References}

Bembridge, T.J., 1984. A systems approach study of agricultural development problems in Transkei. PhD dissertation, University of Stellenbosch.

Brussow, K.P., Schneider, F. \& Kanitz, W., 1996. Application of GnRH agonists in young sows affects cyclic gonadotropin release. Tierartztl. Prax. 3, 248-255.

Burns, P.D., Spitzer, J.C., Burns, G.L. \& Plyler, G.L., 1993. Inhibition of estrus and corpus luteum function with Norgestomet. Theriogenology 39, 863-873.

Chang, M.C., 1985. Inhibition of fertilization in the rabbit long after injection of Depo-Provera. Fertil. Steril. 43, 652-655.

Chemineau, P., Malpaux, B., Delgadillo, J.A., Guérin, Y., Ravault, J.P., Thimonier, J. \& Pelletier, J., 1992. Control of sheep and goat reproduction: Use of light and melatonin. Animal Reproduction Science 30 (1-3), 157-184.

Clarke, I.J., Fraser, H.M., McNeilly, A.S., 1979. Active immunization of ewes against luteinizing hormone releasinghormone, and its effects on ovulation and gonadotropin-releasing hormone neutralization. Endocrinol. 110, 11161123.

D’Occhio, M.J., Fordyce, G., Whyte, T.R., Jubb, T.F., Fitzpatrick, L.A., Cooper, N.J., Aspden, W.J., Bolam, M.J. \& Trigg, T.E., 2002. Use of GnRH agonist implants for long-term suppression of fertility in extensively managed heifer and cows. Anim. Reprod. Sci. 75, 151-162.

Daels, P.F. \& Hughes, J.P., 1995. Fertility control using intrauterine devices: An alternative for population control in wild horses. Theriogenology 44, 629-639.

DeMatteo, K., Silbur, S., Porton, I., Lenahan, K., Junge, R. \& Asa, C., 2005. Preliminary tests of a new reversible male contraceptive in Bush dog (Speothos venaticus), open ended vasectomy and microscopic reversal. J. Zoo Wildlife Med. 37, 313-317.

Denicola, A.J., Kesler, D.J. \& Swihart, R.K., 1997. Dose determination and efficacy of remotely delivered norgestomet implants on contraception of white-tailed deer. Zoo. Biol. 16, 31-37.

Dunbar, B.S., Prasad, S., Carino, C. \& Skinner, S.M., 2001. The ovary as immune target. J. Soc. Gynecol. Investig. 8(1), 43-48.

Esbenshade, K.L. \& Brit, J.H., 1985. Active immunization of gilts against gonadotropin-releasing hormone: Effects on secretion of gonadotropin, reproductive function, and response to agonists of gonadotropin-releasing hormone. Biol. Reprod. 333, 569-577.

Fordyce, G., Jubb, T.F., Fitzpatrick, L.A., Whyte, T.R., Cooper, N.J., Bolam, M.J., Haddon, D.J., Hill, F. \& D'Occhio, M.J., 2001. Contraceptive efficiency of an intra-uterine device in Brahman cattle. Anim. Reprod. Sci. 65, 193-204.

Frank, K.M. \& Kirkpatrick, J.F., 2002. Porcine zona pellucida immunocontraceptive in captive exotic species: Species differences, adjuvant protocols, and technical problems. In: Proceedings, American Association of Zoo Veterinarians, Milwaukee, Wis. 221-223. 
Frank, K.M., Lyda, R.O. \& Kirkpatrick, J.F., 2005. Immunocontraception of captive exotic species: IV. Species differences in response to the porcine zona pellucida vaccine, timing of booster inoculations and procedural failures. Zoo Biol. 24, 349-348.

Garza, F. Jr, Thompson, D.L., Jr, French, D.D., Wiest, J.J., St George, R.L., Ashley, K.B., Jones, L.S., Mitchell, P.S. \& McNeill, D.R., 1986. Active immunization of intact mares against gonadotropin-releasing hormone: Different effects on secretion of luteinizing hormone and follicle-stimulating hormone. Biol. Reprod. 2, 347-352.

Hafez, E.S.E., 1952. Studies on the breeding and reproduction of the ewe. Journal of Agricultural Science 42, $189-265$.

Jacobsen, N.K., Jessup, D.A. \& Kesler, D.J., 1995. Contraception in captive black-tailed deer by remotely delivered norgestomet ballistic implants. Wild Soc. Bul. 23, 718-722.

Janett, F., Lanker, U., Jörg, H., Meijerink, E. \& Thun, R., 2009. Suppression of reproductive cyclicity by active immunization against GnRH in the adult ewe. Schweiz Arch. Tierheilkd. 151, 53-59.

Jöchle, W., Gimenez, T., Esparza, H. \& Hidalgo, M.A., 1973. Preparation of teaser bulls, rams and boars by penis and prepuce deviation. Vet. Med./Small Anim. Clin. 68, 395-400.

Johnson, H.E., DeAvilla, D.M., Chang, C.F. \& Reeves, J.J., 1988. Active immunization of heifers against luteinizing hormone releasing-hormone, human chorionic gonadotropin hormone and bovine luteinizing hormone. Anim. Sci. 66, 719-726.

Keeling, B.J. \& Creighton, D.B., 1984. Reversibility of the effects of active immunization against LHRH. In: D.B. Creighton (ed). Immunological aspects of reproduction in mammals. Butterworth, London. pp. 370-397.

Kirkpatrick, J.F., Calle, P.P., Kalk, P., Liu, I.K.M. \& Turner, J.W., 1996. Immunocontraception of captive exotic species. II. Formosan sika deer (Cervus Nippon taiouwanus), axis deer (Cervus axis), Himalayan tahr (Hemitragus jemlahicus), Roosevelt elk (Cervus elaphus roosevelti), Reeves's muntjac (Muntiacus reevesi) and samber deer (Cervus unicolor). J. Zoo Wild Med. 27, 482-495.

Maclellan. L.J., Bergfeld, E.G.M., Earl, C.R., Fitzpatrick, L.A., Aspden, W.J., Kinder, J.E., Walsh, J., Trigg, T.E. \& D'Occhio, M.J., 1997. Influence of the luteinizing hormone releasing hormone agonist, deslorelin, on patterns of estradiol-17 $\alpha$ and luteinizing hormone secretion, ovarian follicular responses to superstimulation with folliclestimulating hormone and recovery and in vitro development of oocytes in heifer calves. Biol. Reprod. 56, 878-884.

Matschke, G.H., 1976. Non-efficacy of mechanical birth control devices for white-tailed deer. J. Wildl. Manag. 40, 792795.

McNeilly, A.S. \& Fraser, H.M., 1987. Effect of gonadotropin-releasing hormone agonist-induced suppression of LH and FSH on follicle growth and corpus luteum function in the ewe. J. Endocrinol. 115, 273-282.

Mucina, L. \& Rutherford, M.C. (eds), 2006. The vegetation of South Africa, Lesotho and Swaziland. Strelitzia 19, South African National Biodiversity Institute, Pretoria.

Munson, L., 2002. Reproductive diseases resulting from contraceptive treatments. In: Proceedings of the Second International Symposium on ART for the Conservation \& Genetic Management of Wildlife. Omaha, NE. pp. 143150.

Nie, G.J., Johnson, K.E., Braden, T.D. \& Wenzel, J.G.W., 2003. Use of an intra-uterine glass ball protocol to extend luteal function in mares. J. Eq. Vet. Sci. 23, 266-273.

Paterson, M. \& Aitken, R., 1990. Development of vaccines targeting the zona pellucida. Curr. Opinions Immunol. 2, 723747.

Patton, M.L., Esbenshade, K.L. \& Flowers, W.L., 1991. Impairment of follicular development by intra-ovarian infusion of gonadotropin-releasing hormone antiserum in prepubertal pigs. J. Reprod. Fertil. 93, 393-398.

Patton, M.L., Jöchle, W. \& Penfold, L.M., 2007. Review of contraception in ungulate species. Zoo Biology 26, 311-326.

Patton, M.L., Penfold, L.M. \& Jöchle, W., 2005. Contraception in ungulates. In: C.S. Asa \& I. Porton (eds). Wildlife contraception: Issues, methods, and applications. The Johns Hopkins University Press, Baltimore, MD. pp.149167.

Porton, I. \& Hornbeck, B., 1993. A North American contraceptive database for ungulates. Int. Zoo Yearbook 32, 155-159.

Raphael, B.L., Calle, P.P., Karesh, W.B. \& Cook, R.A., 1992. Contraceptive program at the New York Zoological Society Institutions. In: Proceedings, Joint Meeting American Association of Zoo Veterinarians and American Association of Wildlife Veterinarians, Oakland, CA. pp.102-103.

Rust, T., Goosen, W.J. \& Mbathsa, Z., 2015. Characterization of production outputs and ewe flock structure of communal wool sheep in Ngqolowa, Eastern Cape. Applied Animal Husbandry and Rural Development 8, 6-18.

Steyn, G.J., 1982. Livestock production in the Amatola basin. MSc. dissertation, University of Fort Hare.

Thimonier, J., Terqui, M. \& Chemineau, P., 1986. Conduite de la reproduction de petits ruminants dans les differentes parties du monde. Proc. Int. Atomic Energy Agency, Vienna. pp. 135-47.

Turin, E.M., Nagle, C.A., Lahoz, M., Torres, M., Turin, M., Medizabal, A.F. \& Escofet, M.B., 1997. Effects of a copperbearing intrauterine device on the ovarian function, body weight gain and pregnancy rate of nulliparous heifers. Theriogenology 47, 1327-1336.

Turner, A. \& Kirkpatrick, J.F., 2002. Effects of immunosuppression on population, longevity and body condition in wild mares (Equus caballus). Reprod. Suppl. 60, 187-195.

Zimbelman, R.G., Lauderdale, J.W., Sokolowski, J.H. \& Schalk, T.G., 1970. Safety and pharmacologic evaluations of melengesterol acetate in cattle and other animals: A review. J. Am. Vet. Med. Assoc. 157, 1528-1536. 